\title{
NEUROFIBROSARCOMA OF THE SMALL INTESTINE ASSOCIATED WITH VON RECKLINGHAUSEN'S DISEASE
}

\author{
By A. G. H. Clay, M.B., B.Chir.
}

Neurofibromatosis, or Von Recklinghausen's Disease (Von Recklinghausen, 1882), is an uncommon though well-known condition. The classical triad of cutaneous pigmentary lesions, tumours of the skin and multiple tumours of peripheral nerve may or may not be present in any one case. Associated with these, various skeletal changes, e.g. scoliosis, localized hypertrophy and sub-periosteal cysts (Miller, 1936), and also endocrine (Tucker, 1924) and developmental abnormalities are inconstantly present. The subject is reviewed by Kinnier Wilson (1940), who gives a full bibliography.

Malignant change occurs frequently in neurofibromatosis. Hosoi (193I) in a statistical review of 446 cases of Von Recklinghausen's Disease, finds evidence of sarcomatous degeneration in 59 cases, an incidence of 13 per cent. Stewart and Copeland (1931), in an extensive survey of neurogenic sarcoma give details of 21 cases in which the cutaneous manifestations of Von Recklinghausen's Disease were present. They find the greatest age incidence in the periods $1-10$ years and 30-50 years. The sex incidence is approximately equal. These authors give a bibliography of the subject.

The origin and histological classification of the malignant tumours of peripheral nerves has been much discussed in the literature. The whole subject is reviewed and condensed by Ewing (1940). He describes three cell types of neurogenic sarcoma, varying in degree of differentiation, and corresponding in general to the rate of growth of the tumour.

Local recurrence after surgical removal may be in the same place, or a new tumour may occur in a different site, either as an independent new growth, or by extension within the nerve sheath. True embolic metastases occur in about 20 per cent. of cases, according to Stout (1935). They are found chiefly in the lungs.

Neurofibrosarcomata are found chiefly arising from peripheral nerves or nerve roots. They may also arise from various viscera. In the alimentary tract a number of cases have been described in the literature. They are thought to arise from the autonomic nervous system in the bowel wall. (Ewing, 1940).

Sarazanes is quoted by Ewing (1940) as having described a number of cases arising in the alimentary tract from the lips to the anus. In the available literature there are reports of 14 cases of neurofibrosarcoma of the small bowel, of which 3 arose in the duodenum and the remainder in the jejunum or ileum. There is a diverse symptomatology in those cases which are fully reported ; one of those described by Miller and Frank (1939) (which was not accompanied by Von Recklinghausen's Disease) was otherwise similar to the present case. A woman of 72 with a two years' history of vague ill-health was found to have asoft mass in the lower abdomen. The pre-operative diagnosis was right ovarian cyst. At operation an almost exactly similar state of affairs was found as in the case described below.

A somewhat similar clinical picture is shown by certain benign neurofibromata of the abdominal viscera ; such a case as this was recently reported by Mimpriss (1947), in which the tumours originated in the stomach. Pre-operative radiological diagnosis was facilitated by involvement of the lumen of the organ.

The literature of neurogenic sarcoma' of the small bowel is briefly reviewed by Hamilton $e t$ al. (1944), who reports a case which was presented with acute intestinal haemorrhage. This patient showed the cutaneous stigmata of Von Recklinghausen's Disease.

In view of the diagnostic difficulties encountered, it is considered that the present case is worthy of being placed on record.

\section{Case Record}

The patient, a married woman of 46 , with no history of any previous illness, was admitted to hospital on October 15, 1946, complaining of weakness of the legs, tiredness and breathlessness of gradual onset for the previous seven months. This had increased to a degree which had forced the patient to take to her bed for five days before 
admission. She complained of ' slight indigestion' during the last two years. This consisted of unlocalized epigastric discomfort coming on about half an hour after food, and partly relieved by alkaline powders. There had been some loss of appetite during the previous three months. There were no other symptoms. The patient stated that the discoloration and abnormalities of the skin had been present since she could remember. She was the fifth of a family of seven, all of whom are alive and well. There was no discoloration of the skin, or other abnormality, in any of the brothers or sisters, and the mother and father were also unaffected as far as the patient was aware.

Menstrual history : Menarche 17 years. Periods regular : scanty flow. No pregnancies.

On admission (October 15, 1946) the patient was well nourished, but pale and listless. The tongue was pale but not smooth. There was a yellowish-brown generalized pigmentation of the face, trunk and arms.

There were five types of skin lesions :

(a) Closely set brownish macules (freckles).

(b) Clear-cut uniformly pigmented areas of brownish colour ('cafe-au-lait patches').

(c) Small circumscribed fibromata about the size of a lentil.

(d) Pedunculated flaccid papillomata (" raisins sans pépins' of French writers).

(e) Several hairy moles.

There were no subcutaneous tumours or nodules palpable. The lymphatic glands were not enlarged. Cardiovascular and respiratory systems were normal. The liver edge was palpable one inch below the costal margin. The spleen was not felt. There was an ill-defined mass in the hypogastrium, slightly to the left of the midline. It was soft and cystic, freely mobile and not tender. Rectal examination revealed no abnormality. There was a right internal concomitant strabismus, but no other abnormality in the central nervous system. The urine contained a trace of albumen only.

Pelvic examination (Mr. S. C. Anderson). Bimanual examination confirmed the presence of a cystic swelling, which was felt in the left fornix. This was not so easy to palpate vaginally as had been expected from the abdominal examination. The uterus was small, ante-verted and separated from this swelling. The right fornix was clear.

Blood count (October 17, 1946). Haemoglobin 40 per cent. Red cells 3 million. Marked hypochromia and anisocytosis. White cells 25,000. Polymorphonuclear leucocytosis.

Radiological examination of the skeleton, which was carried out at a later date, revealed no abnormality.
Progress. An intermittent pyrexia up to $102^{\circ} \mathrm{F}$. persisted, and there was a gradual deterioration in the patient's general condition.

The pelvic mass was at first considered incidental to a clinical picture of pyrexia, anaemia and leucocytosis, and the following investigations were among those carried out :

Fractional Test Meal: Showed free hydrochloric acid present.

X-ray of Chest : N.A.D.

Stool : Occult blood, negative.

W.R. : Negative.

A further blood count on October 25, 1946, showed : Haemoglobin 30 per cent. Red cells 2.9 million. Reticulocytes 3.8 per cent. E.S.R. $20 \mathrm{~mm}$. (Wintrobe). W.B.C. 22,100. Polymorphs 8I per cent.

Treatment was continued with blood transfusions and penicillin (1.4 mega units in 7 days). There was much improvement following this treatment, and the patient became apyrexial.

Radiography after an opaque enema showed no significant abnormality. X-ray examination after an opaque meal revealed a paraoesophageal hiatus hernia. The possible significance of this finding is discussed below. There was no delay in passage of the bowel contents, and no other abnormality was found.

In view of an increase in the size of the pelvie mass, laparotomy was decided upon, with tentative diagnosis of malignant tumour of the left ovary. Sarcomatous degeneration of a neurofibroma had been suggested as an alternative.

Operation. November 22, 1946. (Mr. S. C. Anderson.)

Midline sub-umbilical incision. A soft cystic, vascular mass, equivalent in size to a 16-week pregnancy, was found in the lower abdomen, adherent to loops of bowel, to bladder and anterior abdominal wall. Very vascular adhesions were separated, during which the cyst ruptured. Brown coloured fluid, about one pint in quantity, and malignant debris escaped. The base of the cyst was the anti-mesenteric border of a loop of the ileum. The bulk of the friable cyst was removed, leaving a very vascular bleeding base. There was no evidence of bowel obstruction or metastasis. The portion of small bowel containing the growth was exteriorized by means of a glass rod. The abdomen was closed below it.

November 24, 1946. Persistent vomiting of all fluids. Abdomen soft and not distended. . Operation by Mr. A. Rendle Short : Resection of small intestine 5-6 in. on each side of the growth. End to end anastomosis performed. Subsequent convalescence uneventful.

The patient was re-examined on March $3 \mathrm{I}$,

$$
\text { . }
$$


1946, I8 weeks after operation. She appeared fit and well, and had put on a considerable amount of weight. She was free of all symptoms, and was able to do her usual housework without distress.

Blood count. March 31, 1947. Haemoglobin 108 per cent. R.B.C. 5.45 million. W.B.C. 8,200 . Polymorphs 70 per cent. E.S.R. I $5 \mathrm{~mm}$. per hour (Wintrobe).

\section{Pathological Report}

Naked eye examination. The specimen measured about $13 \mathrm{~cm}$. by $9 \mathrm{~cm}$. after rupture and evacuation of fluid. It consisted of a base of lobulated, solid tumour tissue about $4 \mathrm{~cm}$. thick, and a large, thin cyst wall. The tumour was haemorrhagic and friable, with an irregular surface where it had been adherent to surrounding structures.

Histological examination. (Dr. F. J. W. Lewis.) The bulk of the tumour was necrotic, sections taken from a viable portion show interlacing bundles of fibroblasts in whorl formation. The nuclei were dark and there was a fair degree of pleomorphism. There were no obvious mitoses. The blood-vessels were quite prominent and thinwalled. The general picture was that of a neurofibrosarcoma. (Fig. I.)

\section{Discussion}

The following points are noted: Firstly, the absence of symptoms referable to bowel disorder, and secondly the severe degree of anaemia (with leucocytosis), despite the absence of detectable bleeding. While this can be accounted for by the presence in the body of a malignant tumour (even in the absence of ulceration of the mucosa), the incidental finding of a para-oesphageal hernia is of interest in this respect. According to Murphy and Hay (1943), anaemia is a frequent and important finding in this condition. In view, however, of the complete recovery of the blood picture following the removal of the tumour in the present case, this finding can be disregarded.

Owing to the small number of these cases so far reported, it is not possible to obtain from the literature any clear idea of the prognosis. Stewart and Copeland (I93I) report that those cases of neurogenic sarcoma showing signs of Von Recklinghausen's Disease have a poor prognosis, due to the multiple involvement of nerve trunks. No case in this group was free of disease for five years. No intestinal cases are reported by these authors.

There is no complete agreement on the proper method of treatment of these cases. The rate of local recurrence after excision is high (Stout, 1935). The whole question of treatment is dealt with by Stewart and Copeland (I93I) and they advise surgical excision in the more malignant cases. Radiotherapy is successful only in the low grade tumours.

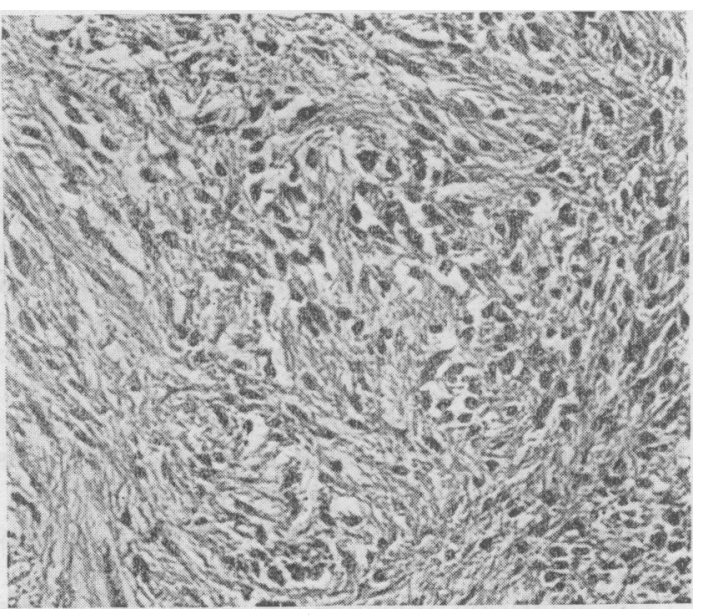

FIG. I.

In the present case, in view of the rupture of the cystic growth during operation, the outlook must be regarded as uncertain.

Finally, it is considered that the presence in a subject showing the cutaneous manifestations of Von Recklinghausen's disease, of indefinite symptoms, or of signs referable to intra-abdominal disease, should at once raise the possibility of malignant degeneration of a visceral neurofibroma.

\section{Summary}

A case is described of progressive anaemia with pyrexia and leucocytosis in a patient showing the cutaneous signs of Von Recklinghausen's disease:

A lower abdominal mass appeared to be an ovarian cyst. Operation revealed a malignant growth of the ileum, which microscopy proved to be a neurofibrosarcoma.

The chief features of neurofibromatosis and malignant degeneration of visceral tumours are briefly described.

Attention is drawn to the importance of considering the possibility of such change in a subject showing the skin lesions of neurofibromatosis.

Acknowledgement. I am indebted to Dr. H. J. Orr-Ewing and to Mr. A. Rendle Short, Physician and Surgeon in charge of this case, and to Dr. P. Phillips, Medical Superintendent, for permission to publish this account. My thanks are also due to Dr. F. J. W. Lewis for the photograph and the histological report.

\section{BIBLIOGRAPHY}

EWING, J. (1940), 'Neoplastic Diseases,' 4th Edn., p. 159. HAMILTON, J. B., et al. (1944), Ann. Surg., I19, 856. HOSOI, K. (1931), Arch. Surg., 22, 258.

KINOI, K. (I931), Arch. Surg., 22, '258. MILLER, A. (1936), Arch. Surg., 32, 109.

MILLER, A. J., FRANK, L. W.' (1939), Ann. Surg., 109, 246. MIMPRISS, T. (1947), Proc. Roy. Soc. Med., 72, 58.

MURPHY, W. P.. HAY, W. E. (1943), Arch. Int. Med., 72, 58. RECKLINGHAÜSEN, 'VON (I882), 'u. d. mult. Fibromen d. Haut.'

STEWART, F. W., COPELAND, M. M. (1931), Am. F. Cancer,

STOUT, I, A. P. (1935), Ibid., 25, I. 